\title{
Current evidence and outcomes for retinopathy of prematurity prevention: insight into novel maternal and placental contributions
}

\author{
Lara Carroll (1), Leah A. Owen* (1) \\ Department of Ophthalmology and Visual Sciences, University of Utah, Salt Lake City, UT 4132, USA
}

*Correspondence: Leah A. Owen, Department of Ophthalmology and Visual Sciences, John A. Moran Eye Center, University of Utah School of Medicine, 65 Mario Capecchi Drive, Salt Lake City, UT 4132, USA. leah.owen@hsc.utah.edu

Academic Editor: Lindsay A. Farrer, Boston University, USA

Received: October 21, 2019 Accepted: November 27, 2019 Published: February 29, 2020

Cite this article: Carroll L, Owen LA. Current evidence and outcomes for retinopathy of prematurity prevention: insights into novel maternal and placental disease contributions. Explor Med. 2020:4-26. https://doi.org/10.37349/emed.2020.00002

\begin{abstract}
Retinopathy of prematurity (ROP) is a blinding morbidity of preterm infants, which represents a significant clinical problem, accounting for up to $40 \%$ of all childhood blindness. ROP displays a range of severity, though even mild disease may result in life-long visual impairment. This is complicated by the fact that our current treatments have significant ocular and potentially systemic effects. Therefore, disease prevention is desperately needed to mitigate the life-long deleterious effects of ROP for preterm infants. Although ROP demonstrates a delayed onset of retinal disease following preterm birth, representing a potential window for prevention, we have been unable to sufficiently alter the natural disease course and meaningfully prevent ROP. Prevention therapeutics requires knowledge of early ROP molecular changes and risk, occurring prior to clinical retinal disease. While we still have an incomplete understanding of these disease mechanisms, emerging data integrating contributions of maternal/placental pathobiology with ROP are poised to inform novel approaches to prevention. Herein, we review the molecular basis for current prevention strategies and the clinical outcomes of these interventions. We also discuss how insights into early ROP pathophysiology may be gained by a better understanding of maternal and placental factors playing a role in preterm birth.
\end{abstract}

\section{Keywords}

Retinopathy of prematurity, prevention, therapeutics, placenta

\section{Introduction}

Retinopathy of prematurity (ROP) represents a significant clinical problem accounting for up to $40 \%$ of childhood blindness worldwide with an estimated incidence of $68 \%$ in infants born less than $1,250 \mathrm{~g}$ [1-3]. With increasing viability of earlier gestational age (GA) infants worldwide, the incidence of ROP is increasing prompting concern for a "third epidemic", particularly in middle or low-income countries [4]. ROP ranges in severity, though even mild disease that clinically regresses is associated with long-term visual impairments [5-8]. Thus, the scope of the problem is increasing, making the life-long burden of blindness in 
this population an even greater clinical concern.

ROP is a disorder of retinal vascular maturation with unclear molecular etiology; early birth, low birth weight (BW), and post-natal oxygen exposure are the only universally accepted independent disease predictors [9-12]. In humans, full retinal vascularization does not developmentally occur until approximately 36-40 weeks corrected GA. Therefore, when born preterm, retinal vascularization is incomplete and must occur in an environment dissimilar to the in-utero environment. ROP represents aberrancy in this process and occurs in two phases. The initial phase occurs prior to 34 weeks GA and is defined by relative hyperoxia and arrest of retinal vascularization. The second phase occurs after 34 weeks and is defined by retinal hypoxia and the manifestation of clinical retinal disease, chiefly pre-retinal neovascularization at the junction of vascularized and a vascular retina $[9,10,13]$. Thus, only the second phase of ROP demonstrates retinal neovascular disease and potentially permanent changes in retinal architecture.

On the basis of this understanding, intervention in the "pre-clinical" phase 1 disease would allow for facilitation of normal retinal vascularization and prevent progression to the second phase of ROP. This necessitates an understanding of early ROP risk and disease mechanisms, occurring prior to and within the first phase of ROP. While overall these are incompletely understood, there has been a significant effort to better delineate early ROP pathological mechanisms [10,11, 14-16]. Work from our group and others substantiates that only low BW, prematurity and post-natal oxygen exposure confer independent ROP risk [9-11, 15, 17-19]. Our current screening metrics, based on this understanding of risk, include GA at birth and BW; however, the specificity of these metrics is only approximately $50 \%[9,10]$. Further, while post-natal oxygen is the most modifiable risk, limiting oxygen increases infant mortality $[9,20,21]$. As a result, our screening is imprecise and current interventions are unable to modify risk and instead, target ROP once retinal disease is present and we are unable to restore normal retinal architecture and visual function [22, 23]. Further, treatment is indicated only in advanced disease with a high probability of retinal detachment and therefore the goal of treatment is largely to prevent this outcome. While our interventions do often achieve this goal, current gold standard treatments are associated with significant ocular and visual morbidity, including retinal scarring, loss of peripheral vision, degenerative myopia and cataract. Therefore, there is significant clinical need for novel understanding of early ROP risk and disease mechanisms to increase screening specificity and prevent retinal disease, facilitating normal retinal vascularization.

Herein, we review key early molecular disease pathogenesis that has informed treatment and prevention therapies, clinical findings based on these interventions, novel insights from maternal, and placental pathobiology to identify ROP disease prevention strategies.

\section{Established ROP patho-mechanisms}

While ROP early risk and mechanisms are incompletely understood, we have greater understanding of the "final common pathway" mediating neovascular retinal disease.

Studies have shown that birth and the consequent switch to lung ventilation produces a change in arterial blood oxygen tension significantly above that of the intrauterine fetus [24]. In the incompletely vascularized preterm infant retina, this "supra-physiologic" tissue oxygenation is felt to initiate the first phase of ROP. During this hyperoxic phase, angiogenic factors such as vascular endothelial growth factor (VEGF) and growth factors such as insulin growth factor 1 (IGF-1) are down-regulated. These molecular changes correlate with arrest of retinal vascularization and pruning of newly formed vasculature leading to retinal avascularity. This process is potentiated by the necessary use of supplemental oxygen, which may also contribute to oxygen toxicity when the production of reactive oxygen species exceeds the capacity of the neonate's antioxidant defense mechanisms, causing apoptosis and further regression of newly formed vessels [25-27]. When the pre-term infant reaches approximately 32-34 weeks, the growing retina experiences an upward shift in its metabolic demands, prompting the second phase of ROP defined by a period of relative hypoxia $[13,15]$. In this context, retinal astrocytes and Muller glia have been shown to up-regulate production of VEGF, IGF-1 and other growth factors [28], resulting in the appearance of proliferative neovascularization characterized by growth of disorganized leaky capillaries into the vitreous. 
This neovascular event has the potential for greatest visual harm as the vitreally-directed vessel growth can result in tractional retinal detachment and irreversible blindness. The central events and molecular changes that form the framework of ROP pathology, as summarized in Figure 1, are the basis for current treatment modalities and for some emerging prevention therapies.

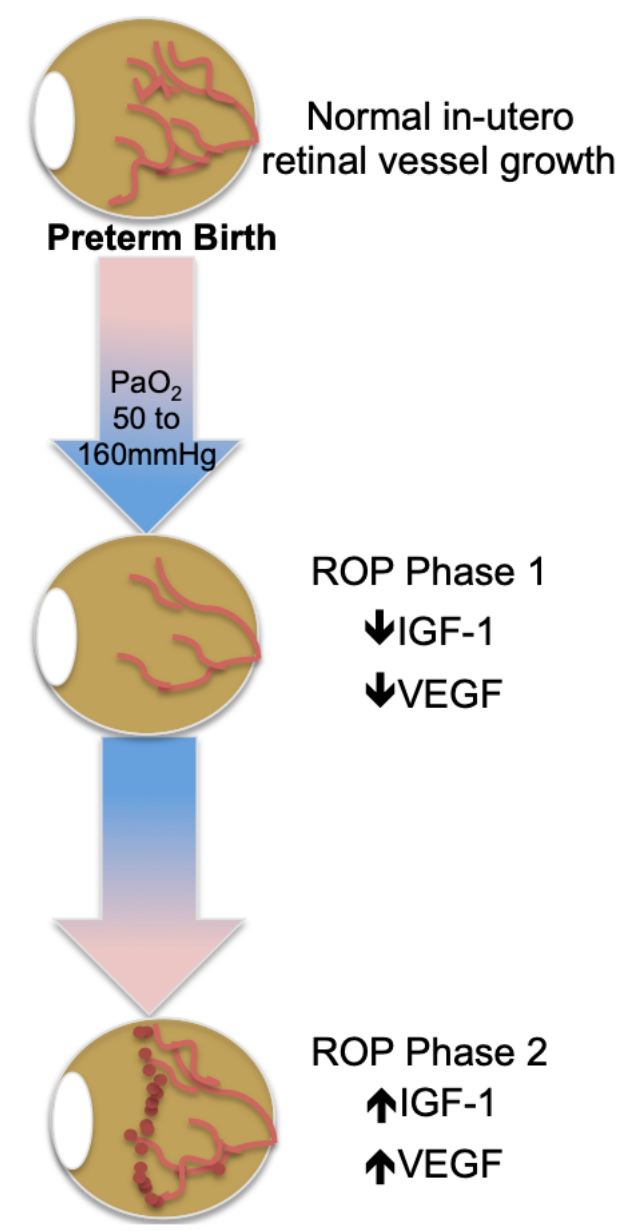

Figure 1. ROP molecular pathogenesis. ROP occurs in two phases following preterm birth and is mediated by a) oxygen; b) VEGF; and c) IGF-1

\section{ROP molecular pathogenesis informs current ROP interventions}

Fluctuations in angiogenic growth factors occurring in the preterm retina and mediating ROP disease are thought to primarily arise from avascular retina [13]. This understanding forms the basis for our current therapeutic interventions, which are aimed at amelioration of neovascularization in the second phase of ROP. These include ablation of avascular retinal tissues, now done with laser, or reduction in expression of the proangiogenic growth factor VEGF and can be administered as a monotherapy or as sequential therapy [29-31].

\section{Anti-VEGF treatment for ROP}

Early studies in animal models of oxygen induced retinopathy (OIR) showed that supplemental VEGF at the onset of hyperoxia significantly decreased both initial vaso-obliteration and the subsequent neovascularization characteristic of ROP, and that inhibition of VEGF was a viable treatment for neovascular disease once established [32-34]. These animal findings were substantiated in humans when use of Avastin, a humanized anti-VEGF monoclonal antibody that had proven effective for pathological retinal neovascularization in adults, was first shown to be efficacious in treatment of ROP [35-37]. However, there is concern for potential adverse local and systemic effects of intraocular anti-VEGF treatments [38-43]. VEGF is now recognized as an important trophic factor for a variety of retinal cell types including retinal neurons, RPE, and glia [44, 45]. The potential for alteration in the development of these retinal cells by broad-based VEGF blockage requires 
further study in the developing eye. Moreover, the potential leakage of anti-VEGF into systemic circulation warrants caution regarding the potentially adverse effects of suppressing VEGF required for extra-ocular physiologic processes [46-49]. Despite the growing use of anti-VEGF therapy in ROP and its support from the American Academy of Ophthalmology and the American Academy of Pediatrics [50], there remains a paucity of information regarding systemic and local safety and efficacy of anti-VEGF therapeutics in ROP disease. Additional controlled clinical studies are needed to provide necessary guidance for optimizing dosage and timing of anti-VEGF injections in preterm newborns for improved standard of care [51].

\section{Ablative therapy for ROP}

Cryotherapy and laser photocoagulation are considered the gold standard ROP treatment [22, 23, 52, 53]. Both methods achieve regression of neovascular retinal disease through ablation of the peripheral avascular retina, eliminating cellular oxygen demand and thereby reducing production of VEGF and other ischemic tissue factors. These treatments greatly reduce neovascularization; nevertheless, ablative treatments can lead to significant peripheral and central vision loss and are further associated with increased risk of cataract and degenerative myopia. Therefore, while these treatments do prevent catastrophic loss of retinal architecture, function, and thus vision, they are associated with significant visual morbidity.

Taken together, our current therapeutic interventions have significant limitations, side-effects, and systemic concerns. Furthermore, they largely lack the ability to restore normal retinal architecture and function through preservation of physiologic retinal vascularization. To this end, work has been done to elucidate mechanisms informing early ROP pathogenesis, within the first phase of ROP, which would allow for intervention prior to development of neovascular disease. These interventions, outcomes and potential for further advancement are reviewed below.

\section{Preventive interventions informed by ROP molecular pathogenesis Oxygen modulation}

Gestational age, BW, and post-natal oxygen supplementation are well-established to be the three greatest risk factors independently informing ROP risk $[10,17]$. Of these risk variables, oxygen exposure is the most modifiable, however modulation of post-natal oxygen has been associated with increased mortality [20, 21, 54] (reviewed by Owen and Hartnett, 2014). Therefore, while increased post-natal oxygen is important for preterm infant neurovascular and lung development, it is deleterious for retinal vascular development. This inverse relationship has overall been prohibitive for ROP prevention strategies based on absolute reductions in post-natal oxygen administration. Despite this, clinical studies continue to examine oxygen variables, such as fluctuation in oxygen saturation, timing, duration, and percent oxygen delivery to establish optimal treatments that can be accommodated to individual infant needs. Although such efforts are gradually delineating the best practices for maximizing preterm infant visual outcomes, there is yet no clinical consensus regarding protocols and target ranges for preterm oxygen therapy, which is particularly true in developing countries with the greatest disease burden [4,54-56]. Various co-morbidities that impact systemic oxygenation such as bronchopulmonary dysplasia [57, 58], thrombocytopenia [59], and anemia $[60,61]$ are also associated with ROP development and/or severity. Interventions targeting these co-morbid conditions, such as transfusion, often show association with more severe ROP disease, though this is likely a surrogate indicator of hypoxia as the etiologic factor [62]. Taken together, data suggest that regulating oxygen alone for co-morbid conditions that contribute to hypoxia does not represent a comprehensive solution for ROP prevention.

\section{Supplemental IGF-1}

IGF-1 is a growth factor critical for normal vascular development, provided in part by the placenta and amniotic fluid during gestation. After term birth, neonate serum levels of IGF-1 decrease; this change is exacerbated in the setting of preterm birth [63]. Further, premature infants who develop ROP have lower serum levels of IGF-1 at birth compared to age-matched infants without disease, suggesting that low IGF-1 is an independent risk factor for subsequent ROP disease [64-67]. However, post-natal growth rate proved to be 
a suitable proxy for IGF-1 levels, and has largely replaced IGF-1 for modeling ROP risk. On a molecular level, decreased IGF-1 has been shown to result in impaired VEGF-mediated endothelial survival and therefore, links IGF-1 function to fundamental ROP pathophysiology [68]. This is supported by rodent studies demonstrating that pharmacological inhibition of IGF-1 prevents VEGF pathway activation, oxygen-mediated vessel loss, and subsequent neovascularization in the OIR model of ROP, suggesting a permissive role of IGF-1 in VEGFmediated retinal neovascularization $[69,70]$. These data have informed current clinical studies to determine if replenishing IGF-1 in preterm infants is preventive for subsequent neovascular proliferation [71]. In a small pilot trial, preterm infants were treated with a continuous infusion of recombinant human IGF-1 (rhIGF-1) and its receptor IGF binding protein-3 (rhIGFBP-3) which demonstrated increased IGF-1 and IGFBP-3 serum concentrations without safety concerns [72]. However, recently published Phase II clinical trials reported no reduction in ROP occurrence or severity after supplemental human rhIFG-I/rhIGFBP-3 administration [73]. As noted by the authors, the IGF-1 treatment effect may be unavoidably masked by high oxygen supplementation; however, as supplemental oxygen continues to be an important part of clinical care, IGF-1 supplementation does not appear to provide a viable monotherapy for ROP prevention. Interestingly, severe bronchopulmonary dysplasia was significantly reduced, and intraventricular hemorrhage showed a downward trend, suggesting that there may be utility to further study of IGF-1 supplementation in preterm neonates. This is substantiated by literature demonstrating a potential role for IGF-1 therapy in treatment of neurodegenerative disease. Specifically, a recent meta-analysis and systematic review demonstrates positive effects of IGF- 1 administration on neuroregeneration in animal models, though clinical study data for human conclusions is limited [74]. Therefore, IGF-1 may play a greater role in future efforts to normalize retinal development.

\section{HIF-1 stabilization}

Hypoxia-inducible factor 1 (HIF-1) is a transcription factor recognized as a master regulator of oxygen response under developmental, physiologic, and pathologic conditions [75, 76]. Under low systemic oxygen, the two HIF- 1 subunits, HIF- $1 \alpha$, and HIF-1 $\beta$, are up-regulated and initiate transcription of hypoxiaresponsive genes, inducing VEGF and other angiogenic factors, prompting vasculogenesis, angiogenesis, and red blood cell production to facilitate increased oxygen delivery to ischemic tissue. On the basis of this molecular function, stabilization of HIF levels during the hyperoxic phase of ROP may prevent initial vascular attenuation and the consequent tissue hypoxia responsible for subsequent neovascular disease. This strategy has been tested in rodents using the OIR model of pre-retinal neovascularization and ROP, with systemic pharmacologic stabilization of Hif- $1 \alpha$ with dimethyloxalylglycine or Roxadustat. Collectively, these studies demonstrated a significant reduction in both avascular retinal area and intravitreal neovascularization relative to control, with no reported adverse effects [77-79]. Based on these data, timely systemic stabilization of HIF-1 may be an effective strategy to promote peripheral vascular development and prevent ROP. However, this approach has limitations when applied to preterm infants; namely, precise therapeutic timing at the onset of hyperoxia is critical as HIF-1 stabilization in the presence of retinal hypoxia may have the undesired effect of exacerbating VEGF-mediated proliferative vascularization [80]. Thus, the opposite therapeutic approach, HIF-1 inhibition (rather than stabilization), is being interrogated as a means to limit VEGF-induced vascularization during the second phase of ROP. In a recent report, topotecan, and doxorubicin, two drugs shown to mediate HIF-1 inhibition through alternate mechanisms, were both found to reduce neovascular tuft formation in mice after systemic administration during the second, hypoxic, phase of the OIR model [81, 82]. These interventions are promising, though prevention approaches are currently limited by incomplete understanding of optimal timing of HIF-1 stabilization and lack of translational human studies.

\section{Caffeine}

Caffeine was first observed to reduce severe ROP outcomes in a randomized multicenter clinical trial examining neurodevelopment and growth in preterm infants treated for apnea of prematurity. At 1821 months, the surviving caffeine treated infants had significantly less severe ROP than placebo infants, with no difference in mortality [83]. Two recent meta-analyses similarly reported a reduction of ROP risk after caffeine treatment in preterm neonates $[84,85]$. This effect has been explored in mouse and rat 
models of OIR [86], which have demonstrated a caffeine-associated decrease in both avascular area and neovascularization of mouse retinas undergoing hyperoxia, supporting a preventive paradigm for caffeine. Similarly, in a rat OIR model, caffeine treatment reduced retinal neovascularization, while co-treatment with topical eye drops containing the non-steroidal anti-inflammatory drug (NSAID) ketorolac, further decreased severe angiogenesis [87]. The molecular basis that informs this therapeutic effect is not completely clear and may in part be related to therapeutic NSAID effects [88]. However, caffeine appears to manipulate key ROP molecular pathogenesis. For example caffeine has been shown to regulate endothelial apoptosis and angiogenesis by regulating levels of HIF1 $\alpha$, VEGF, and IGF-1, and by decreasing inflammatory pathways through reduction of NF-kB cyclooxygenase (Cox-2) activity [86, 87, 89]. Early caffeine administration, within the first 2 post-natal days, was recently found to be associated with improved neurodevelopmental outcomes, though studies designed to understand independent prevention or treatment significance fail to demonstrate a role for caffeine administration in ROP management $[10,17,90]$. Therefore, caffeine alone does not appear to offer sufficient ROP prevention.

\section{Beta blockers}

Propranolol, a nonselective beta-adrenoreceptor blocker (B-AR), was initially proposed as a treatment for neovascular ROP disease after it was found effective in reducing the growth of infantile capillary hemangiomas, which demonstrate VEGF-mediated pathogenesis similar to ROP [91]. Propranolol is thought to modulate VEGF function through activation of the B2 and B3 adrenoreceptors, which results in attenuation of vascularization through inhibition of norepinephrine-mediated elevations in HIF-1, IGF-1, and VEGF [92-96]. The effectiveness of propranolol for both prevention [95] and treatment [96-99] of preretinal neovascularization in the murine OIR model demonstrates mixed results, though the preponderance of evidence suggests efficacy. However, studies in preterm infants have raised concern for both efficacy and safety. Although oral propranolol showed promise in halting ROP progression, there was an increase in adverse life-threatening side-effects in pilot clinical trials [100], and a recent multi-center phase IIB study using $0.2 \%$ propranolol in newborns with stage 1 ROP reported that despite overall favorable treatment results, early treatment resulted in worse ROP disease, suggesting that a $\beta$-adrenoreceptor blockade is only useful during the proliferative phase [101]. These findings may harmonize the disparate data with regard to efficacy of propranolol for ROP treatment, but nevertheless raise concern for preventive $\beta$-adrenoreceptor inhibition in ROP. Further, recent studies demonstrate a possible deleterious refractive outcome of topical propranolol therapy, highlighting the importance of continued study [102]. Conversely, a recent meta-analysis including clinical trial and study data for 461 infants, demonstrated efficacy of oral propranolol for ROP prevention in preterm infants demonstrating a decreased relative risk of severe ROP disease (not complete ROP prevention), supporting prior PreROP trial data $[103,104]$. However the authors do note that additional well-powered, multinational, randomized control trials reporting on long-term outcomes are needed.

\section{Human breast milk}

Perinatal inflammation [105-107] and nutritional deficiencies [108-110] are postulated to render the developing retina more susceptible to ROP pathogenesis. Nutritional deficiencies in polyunsaturated fatty acids (PUFAs), inositol, vitamins A, E, and D supplied in human breast milk (BM) are known to increase inflammation and oxidative stress and therefore these processes are likely inter-related. Increased levels of inflammatory markers have been identified in placentas from preterm births associated with increased ROP risk, as well as in newborn and maternal serum from such pregnancies [105]. Further, the contribution of global nutritive status, as measured by post-natal weight gain, has an increasingly recognized contribution to early ROP risk; models incorporating these factors into risk stratification can improve prediction accuracy for ROP, ultimately reducing the number of preterm neonates subjected to eye exams [19, 111-114]. Human BM contains immunoglobulins, digestive enzymes, important nutrients such as docosahexaenoic acid (DHA) and inositol, as well as maternally transferred vitamins such as vitamins A, C, D, E, and K, riboflavin and niacin, and most studies show a decreased association of ROP in preterm infants fed mothers milk [115-118]. However there may be nutritional differences in preterm and term BM that can affect clinical outcomes [108]. We are beginning to quantify these differences and optimize our abilities to provide preterm infants with key 
nutritional components in BM $[119,120]$. With increased understanding of nutritional and inflammatory differences in the preterm neonate, as well as the interplay between these factors, we will be better able to understand the preventive role for BM supplementation in ROP pathogenesis. Based on current evidence, this is not a viable prevention strategy at present.

\section{Vitamin E supplementation}

The first nutritional and antioxidant supplement to be tested in preterm neonates for improving ROP outcome was vitamin E [121]. However, in the 70 years since its off-label use, a multitude of observational and controlled clinical studies have not clearly delineated benefits of vitamin E supplementation for treating ROP. Although an active clinical trial is currently interrogating the efficacy of a topical formulation of vitamin E plus other antioxidants [122], vitamin E supplementation is no longer considered a viable strategy for ROP prophylaxis, particularly amidst reports of increased morbidity.

\section{Inositol supplementation}

Work has also been done to investigate the role for non-maternal milk sources of dietary supplements to improve preterm neonate health and prevent development of ROP, though there are mixed results. For instance, while two early clinical studies testing inositol supplementation reported an associated decrease in ROP incidence [123, 124], a recent randomized clinical trial was terminated early after a trend of increased mortality with treatment, and recent systematic reviews and meta-analyses were unable to detect a significant effect of inositol on preventing ROP [125-127].

\section{Vitamin A supplementation}

Vitamin A supplementation demonstrates greater promise for ROP prophylaxis. Systemic concentrations of the vitamin A metabolite retinol are low in preterm infants [128, 129], and observational studies have demonstrated a reduced risk of ROP with aggressive supplementation of vitamin A [130]. The mechanistic role of vitamin A relative to fundamental ROP pathogenesis is not clear, though there is precedent for the importance of vitamin A metabolism for photoreceptor function, retinal health and vision. Specifically, preterm neonates showed improved dark-adapted rod sensitivity when supplemented with high-dose Vitamin A [131]. Moreover, results from the first randomized control trial testing vitamin A supplementation for ROP prevention demonstrated that supplementation with 1,500 IU/day vitamin A was associated with significantly lower risk of Type 1 ROP compared to the control group, with no reported signs of vitamin A toxicity [132]. While certainly promising, vitamin A supplementation did not reduce overall ROP development and therefore, likely does not represent a singular preventive approach.

\section{Polyunsaturated fatty acid supplementation}

Some of the most promising and least contentious supplements currently in clinical trials are the $\omega$-3 longchain PUFAs DHA and eicosapentaenoic acid (EPA). Both have well established benefits in protecting against inflammation and oxidative stress contributing to neurodegeneration [133]. Moreover, these fatty acids play a role in modulating IGF-1 activation [134] and VEGF-mediated endothelial signaling [135,136], and may therefore contribute directly to ROP molecular pathogenesis. Animal studies overall support a role for fatty acid supplementation as treatment and possibly prevention for ROP. Supplementation with DHA and EPA were found to reduce retinal avascular area in mice subjected to hyperoxia, partly by suppression of proinflammatory tumor necrosis factor- $\alpha$ which itself promotes angiogenesis via cooperation with VEGF [137]. Furthermore, dietary omega-3 fatty acid supplementation during the proliferative stage of OIR also improved retinal outcome, greatly reducing neovascularization [138]. However, Beharry et al. [139], found a higher incidence of peripheral hemorrhaging in omega-3 treated pups, possibly due to the anti-thrombotic effects of PUFAs [140]. ROP outcomes after long-chain polyunsaturated fatty acid supplementation have been tested in preterm infants with largely favorable results. In three randomized control trials and a small observational study of very low BW infants, fish oil supplementation (which contains both DHA and EPA) was found to significantly decrease ROP risk or severity [141-144]. A subsequent systematic review and meta-analysis comparing fish-oil lipid emulsions with soybean-based lipid emulsions, reported a significantly reduced 
risk of severe ROP or ROP requiring laser therapy after the fish-oil supplement, suggesting that omega- 3 PUFAs may help prevent development of aggressive ROP [145]. However, no ROP effect was measured in two recent randomized clinical trials testing supplementary fish oil or a mixed lipid emulsion containing soybean oil, medium chain triglycerides, olive oil and fish oil compared to control treatment [142, 146]. In one of two recent randomized clinical trials testing DHA supplementation alone, a decrease in stage 3 (severe) ROP was reported, though neither study found a reduction in overall ROP incidence [147, 148]. These conflicting results may be explained by, a recent study which found that a high ratio of preterm infant erythrocyte omega-6/omega-3 PUFA (ratio of arachidonic acid to DHA) at birth, positively correlated with later development of ROP [149], suggesting that the ratio of omega-6/omega-3 PUFAs rather than absolute levels of omega-3s in blood may be a better predictor of ROP risk. Additional studies are needed to examine the implications of PUFA ratios in a clinical setting, though greater understanding of effective dosing, timing and fatty acid composition may lead to preventive supplementation in the future. A randomized, controlled clinical trial due to be completed in December 2019 testing intravenous omega-3 fatty acid supplementation for ROP prevention will additionally report infant peripheral circulation lipidomic and transcriptomic profile outcomes and thus, may contribute to these knowledge gaps (NCT02486042).

As depicted in Figure 2, current ROP prevention strategies, based on known post-natal ROP pathomechanisms, have failed to demonstrate singular efficacy for disease prevention. In some cases treatments have resulted in deleterious effects. Therefore, additional approaches are necessary to more effectively achieve early intervention that enables us to alter the natural course of disease and promote normal retinal vascularization in the ex-utero environment. While, as some authors have postulated, this may be achieved through combined effects from current strategies that show incomplete benefit, it may also be true that understanding events "up-stream" of post-natal mechanisms may best inform novel prevention strategies.

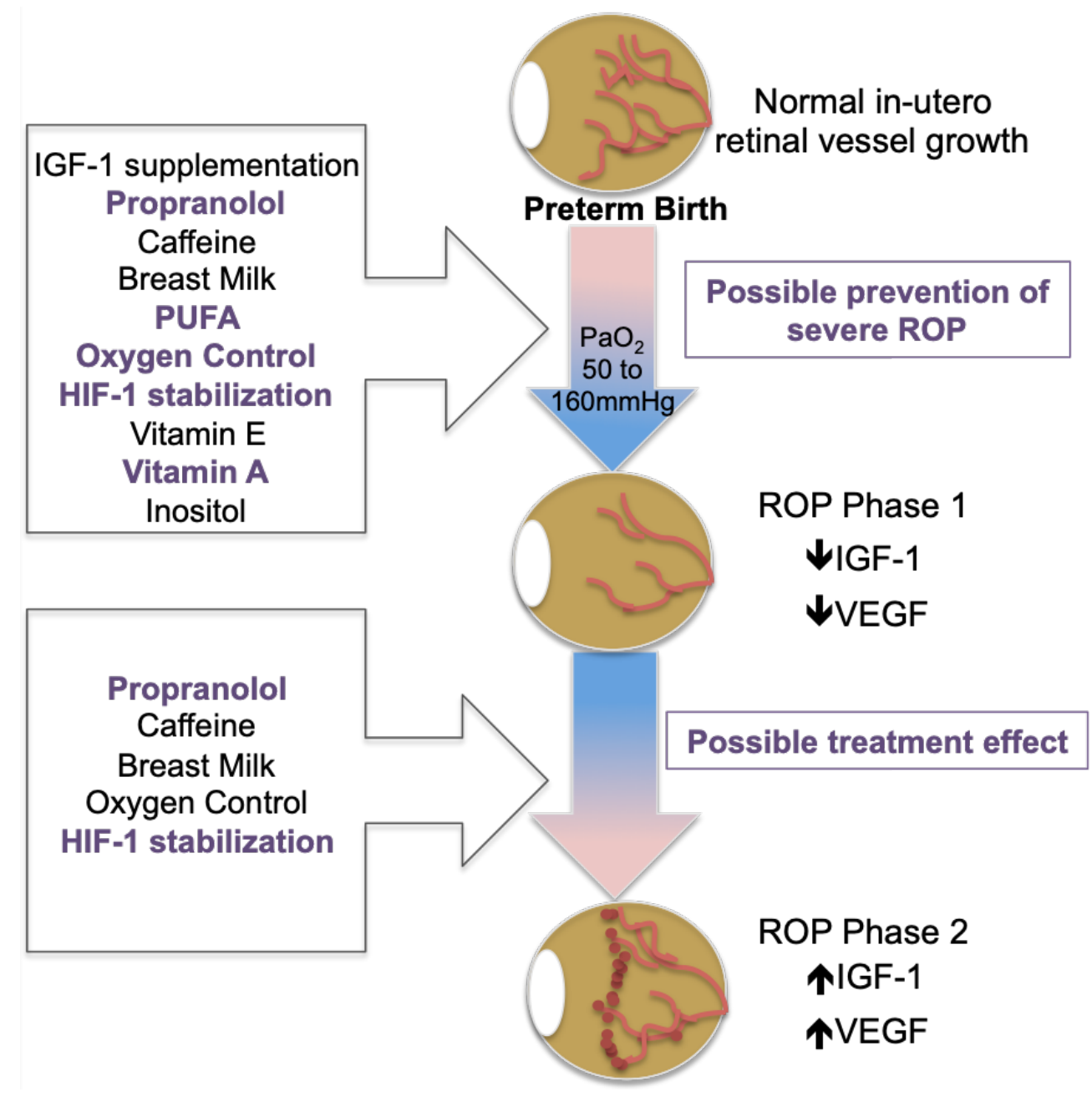

Figure 2. Preventive strategies target post-natal molecular pathogenesis 


\section{A role for maternal and placental contributions in ROP disease}

ROP is typified by a multifactorial etiology with most of our current investigation directed at genetic and environmental risk. Certainly, numerous candidate genes have been identified, including brain derived neurotropic factor, and key factors involved in the canonical Wnt signaling pathway, such as frizzled class receptor-4 and low density lipoprotein receptor-related protein 5. However, none of the allelic variants identified thus far sufficiently impact ROP pathogenesis to inform novel screening, prevention or treatment paradigms as reviewed recently by Swan et al., [150]. The contributions of maternal and placental pathobiology to preterm infant ROP development are under-studied by comparison and thus, poorly understood. Despite, the strong (0.73) heritability factor of ROP predicted from twin studies [10, 105, 151, 152], preliminary work suggests that maternal and placental physiology can influence preterm infant ROP risk in meaningful ways. The placenta is the primary maternal/fetal interface and functions to exchange nutrients and oxygen between the mother and infant. The full complement of injury following deprivation of placental support in preterm birth is not clear, as placental function evolves during fetal maturation. While it is accepted that abrupt loss of placental support is deleterious to global infant development in the immediate postnatal period [153] as exemplified in the Barker hypothesis, long-term health outcomes are also affected by maternal and placental pathobiology including cardiovascular, diabetic and neurologic disease [154-156]. Therefore, an understanding of the maternal and placental fetal support factors lost at the time of preterm birth may provide insight into novel early disease mechanisms, better enabling preterm infant disease prevention.

There is precedent for the influence of placental pathobiology on post-natal preterm infant diseases including bronchopulmonary dysplasia, necrotizing enterocolitis, neurocognitive and neurovascular development [157-163]. Furthermore, preterm infant inflammatory and neurotrophin protein levels at birth, thought to be mediated in-utero by the placenta, are associated with brain volumes and cognition [164]. Preliminary work in ROP similarly has shown that elevated levels of inflammatory proteins in preterm infant systemic circulation at birth is associated with increased ROP risk, whereas a decreased risk of ROP was associated with higher levels of angiogenic and neurotrophic factors [165]. Moreover, a study of CpG methylation profiles in DNA from the placentas of mothers with Extremely Low Gestational Age Newborns (ELGAN) study [166] showed that CpG methylation variability corresponded to infant systemic protein level changes associated with ROP risk [167]. Finally, placental function has been shown to inform fundamental ROP pathological mechanisms, including systemic preterm infant IGF-1 expression [168]. Thus, there is precedent and preliminary evidence for the potential role of maternal and placental pathobiology informing ROP pathogenesis.

\section{A novel model of natural ROP protection}

While simply understanding the influence of maternal/placental physiology and pathobiology on preterm infants may provide a valuable framework for understanding ROP risk and pathological mechanisms, doing so within a natural model of placentally-mediated ROP protection may add further insight into potential therapeutic approaches. This idea is supported by evidence showing that placental pathologies associated with preterm birth, particularly those with intra-uterine infection/inflammation such as chronic or acute chorioamnionitis are generally strongly associated with increased ROP risk [105, 169-171]. However emerging evidence suggests that maternal preeclampsia may represent an exception with respect to ROP risk and severity, and may even represent a natural model of ROP protection, with potential to provide novel understanding of early protective ROP mechanisms. There is considerable support for this relationship in the epidemiologic literature, including recent systematic reviews and meta-analyses [18, 172-179]. Several studies dispute this protective relationship [180-182], or find no association [183], however, these studies are largely limited by small sample size and lack of appropriate controls (GA, BW and presence of preterm labor) and most have suggested larger analyses are needed. The largest studies, up to 25K in one study [172], reproducibly demonstrate ROP protection in preeclampsia. Further, we know that ethnicity, NICU care (i.e. oxygen targets), and infant GA at birth influence the measured affect. This is highlighted in a recent publication by Shulman et al. [176], who found that preterm infants with GA and BW risk for ROP $(<32$ weeks and 1,500 g) demonstrated ROP protection with preeclampsia; however, infants with no GA or BW risk for ROP, GA at 
birth 38 weeks, had an increased co-occurrence of ROP and preeclampsia. Thus, it is important to consider the population demographics when analyzing the relationship between preeclampsia and ROP. These data are further supported by epidemiologic data in other forms of placental insufficiency demonstrating ROP protection [184]. Shulman et al. [176], further suggest that prematurity, while necessary for ROP risk, may confound the measured association between maternal preeclampsia and ROP. Certainly the etiologic basis for preterm delivery is varied in most populations, particularly the relatively smaller population delivering in the ROP risk window prior to 32 weeks gestation. It is possible that the mechanisms informing spontaneous preterm delivery as opposed to induced preterm delivery (as is often the case in maternal preeclampsia) predispose to greater risk of ROP rather than preeclampsia predisposing to lesser ROP risk. This question remains to be answered in humans, although we are beginning to address it with studies controlling for the presence of labor, which demonstrate no ROP effect from preterm labor as opposed to induced or spontaneous (i.e. cervical inconvenience, etc.) preterm delivery [10,17]. This is supported by rodent studies from Becker et al. [185], in which premature birth was uncoupled from uteroplacental insufficiency (UPI, a major component of preeclampsia) using a rat uterine artery ligation model. They found that in the setting of term gestation, uteroplacental insufficiency resulted in a significant decrease in avascular area and a trend towards reduced proliferative vascularization in the OIR model of ROP, supporting a relationship between placental insufficiency and ROP protection at the earliest stages of retinal vascular development [185]. If ROP protection in the setting of preeclampsia is actually the inverse effect-namely an empirically greater risk or ROP from non-preeclamptic spontaneous preterm births-it can still be argued that mechanisms underlying reduced likelihood of ROP development in the setting of preeclampsia will inform approaches toward normalizing retinal vascular development and ROP prevention. Taken together, understanding mechanisms of ROP protection in preeclampsia is a novel strategy to identify earlier ROP risk, informed by maternal and placental pathobiology, which may allow for more efficacious in-utero or postnatal prevention.

There are varied hypotheses regarding mechanisms of ROP protection in the setting of preeclampsia. Preeclampsia is a complex maternal-fetal-placental pathology typified by placental insufficiency of unclear molecular basis; however, a recent systems biology analysis of preeclampsia confirmed prior work and suggested a more comprehensive maternal etiology for preeclampsia [186]. Therefore, mechanisms contributing to preeclampsia, and thereby ROP protection in this setting, are likely multifactorial. Multiple lines of evidence in the literature suggest that placental pathobiology is an underlying factor in our current paradigm of ROP pathogenesis. For example, Becker et al. [185], suggest that increased systemic angiogenic factors are the etiologic basis for ROP protection in their OIR rat model. Although this has been incompletely assessed in humans, preeclampsia in humans involves dysregulation of angiogeneic factors, particularly in the maternal circulation [187-189]. Work from other groups has linked placental function to fatty acid deficit and ROP risk. Macronutrient transport protein expression has been associated with cellular-level placental histologic changes in preeclampsia; specifically, increased fatty acid placental transfer and maternal systemic circulation have been suggested to mediate disease in early onset preeclampsia [190]. As discussed previously, ROP development has been associated with decreased circulating fatty acids longitudinally from birth [191]. Combined, these studies suggest that an integrated systems approach, combining maternal and placental pathobiology relative to preterm infant ROP can elucidate underlying mechanisms of protection that can be therapeutically replicated post-natally or even in-utero to prevent ROP.

While placental evaluation is possible in human disease and demonstrates the greatest translational value, manipulation of risk variables and local tissue (retinal) biochemical and genomic analysis is prohibitive. Preeclampsia/placental insufficiency can be modeled in rodents and ROP outcomes subsequently assessed using the OIR model of ROP. The "gold standard" approach for placental insufficiency is uterine artery ligation, which directly modulates blood flow to the placenta, thereby achieving insufficiency. While, as noted previously, this model of placental insufficiency does demonstrate decreased severity of pre-retinal neovascularization in the OIR model, there are limitations to this approach including the extreme degree and abrupt onset of hemodynamic insufficiency, which likely does not fully recapitulate preeclamptic pathophysiology now believed to be a systemic condition [186]. Alternative models, including chronic systemic delivery of a thromboxane A2 analog which is commonly overproduced in preeclampsia, represents 
a more systemic model of preeclamptic pathophysiology and thus, may better inform relative to the human condition [192-194].

\section{Conclusions}

ROP has significant clinical impact on the life-long vision of preterm infants, even in the setting of mild disease. Our treatments are only indicated in the most severe presentations and are associated with significant visual comorbidity and possible deleterious systemic effects. We currently lack the ability to meaningfully prevent ROP disease and facilitate normal retinal vascularization. While numerous strategies have been tested, to date none have demonstrated sufficient efficacy for complete ROP prevention. Emerging evidence suggests an important role for maternal and placental physiology and pathobiology in preterm infant post-natal and lifelong disease burden, including ROP risk and mechanisms. As depicted in Figure 3, preliminary work suggests a role for maternal and placental contributions to physiologic in-utero mechanisms of normal retinal development as well as known mechanisms informing the current paradigm of ROP pathogenesis. The contribution of placental function to subsequent infant ROP disease is further highlighted in preeclamptic placental insufficiency, which paradoxically demonstrates ROP protection. These contributions are "upstream" of our current understanding and thus may allow for earlier disease prediction and intervention, prior to substantial vessel loss or neovascular retinal disease. We hypothesize that greater understanding of maternal and placental contributions in both the physiologic and pathologic conditions will allow us to advance our understanding of early ROP risk and patho-mechanisms and design novel strategies for not only ROP prevention but also facilitation of normal retinal vascularization for all preterm infants.

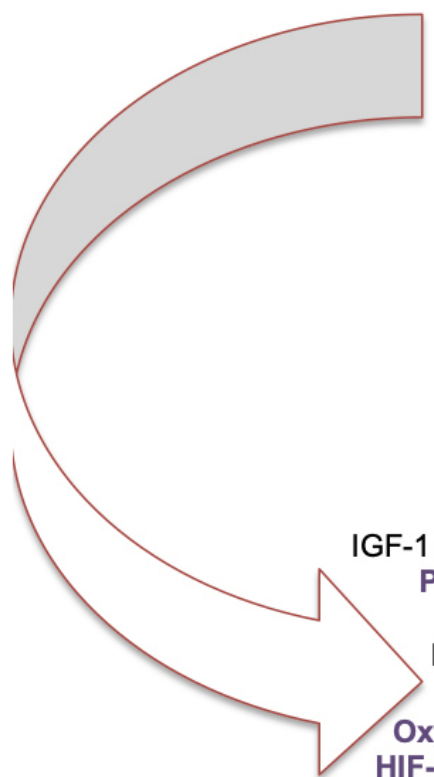

HIF-1 stabilization Vitamin $\mathrm{E}$

Vitamin A Inositol

Caffeine

Breast Milk

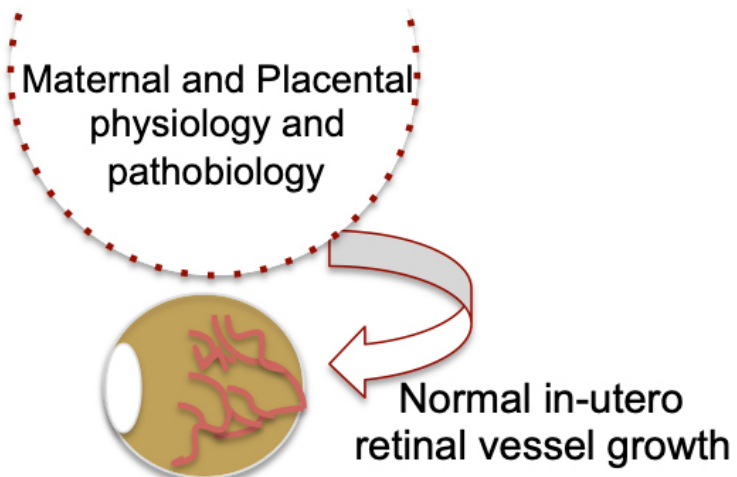

Preterm

Birth

$\mathrm{PaO}_{2}$

50 to

$160 \mathrm{mmHg}$

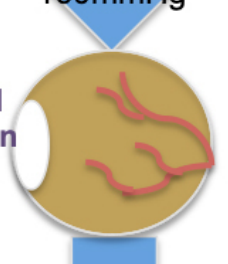

ROP Phase 1

$\downarrow$ IGF-1

$\downarrow V E G F$

Figure 3. Maternal and placental-informed ROP preventive 


\section{Abbreviations}

BM: breast milk

BW: birth weight

DHA: docosahexaenoic acid

EPA: eicosapentaenoic acid

GA: gestational age

HIF-1: hypoxia inducible factor-1

IGF-1: insulin growth factor-1

NSAID: non-steroidal anti-inflammatory drug

OIR: oxygen induced retinopathy

PUFAs: polyunsaturated fatty acids

rhIGF-1: recombinant human IGF-1

rhIGFBP-3: recombinant human IGF binding protein-3

ROP: retinopathy of prematurity

VEGF: vascular endothelial growth factor

\section{Declarations}

\section{Author Contributions}

Both LAO and LC contributed to the conception and design of this review. All authors contributed to manuscript writing and revision, read and approved the submitted version.

\section{Conflicts of Interest}

The authors declare that there are no conflicts of interest.

\section{Ethical Approval}

Not applicable.

\section{Consent to Participate}

Not applicable.

\section{Consent to Publication}

Not applicable.

\section{Availability of Data and Materials}

Not applicable.

\section{Funding}

Research reported in this publication was supported by the Eunice Kennedy Shriver National Institute of Child Health and Human Development and the Office of Research on Women's Health of the National Institutes of Health under Award Number K12HD085852. The Content is solely the responsibility of the authors and does not necessarily represent the official views of the national Institutes of Health. It is also supported by an unrestricted RPB grant to the John Moran Eye Center at the University of Utah.

\section{Copyright}

(C) The Author(s) 2020. 


\section{References}

1. Gilbert C, Foster A. Childhood blindness in the context of VISION 2020--the right to sight. Bull World Health Organ. 2001;79:227-32.

2. Gilbert C, Fielder A, Gordillo L, Quinn G, Semiglia R, Visintin P, et al; International NO-ROP Group. Characteristics of infants with severe retinopathy of prematurity in countries with low, moderate, and high levels of development: implications for screening programs. Pediatrics. 2005;115:e518-25.

3. Good WV, Hardy RJ, Dobson V, Palmer EA, Phelps DL, Quintos M, et al; Early Treatment for Retinopathy of Prematurity Cooperative Group. The incidence and course of retinopathy of prematurity: findings from the early treatment for retinopathy of prematurity study. Pediatrics. 2005;116:15-23.

4. Quinn GE. Retinopathy of prematurity blindness worldwide: phenotypes in the third epidemic. Eye Brain. 2016;19;8:31-6.

5. Harris ME, Moskowitz A, Fulton AB, Hansen RM. Long-term effects of retinopathy of prematurity (ROP) on rod and rod-driven function. Doc Ophthalmol Adv Ophthalmol. 2011;122:19-27.

6. Wu WC, Shih CP, Wang NK, Lien R, Chen YP, Chao AN, et al. Choroidal thickness in patients with a history of retinopathy of prematurity. JAMA Ophthalmol. 2013;131:1451-8.

7. Siatkowski RM, Dobson V, Quinn GE, Summers CG, Palmer EA, Tung B. Severe visual impairment in children with mild or moderate retinal residua following regressed threshold retinopathy of prematurity. J AAPOS. 2007;11:148-52.

8. Siatkowski RM, Good WV, Summers CG, Quinn GE, Tung B. Clinical characteristics of children with severe visual impairment but favorable retinal structural outcomes from the Early Treatment for Retinopathy of Prematurity (ETROP) study. J AAPOS. 2013;17:129-34.

9. Owen LA, Hartnett ME. Current concepts of oxygen management in retinopathy of prematurity. J Ophthalmic Vis Res. 2014;9:94-100.

10. Owen LA, Morrison MA, Hoffman RO, Yoder BA, DeAngelis MM. Retinopathy of prematurity: a comprehensive risk analysis for prevention and prediction of disease. PloS One. 2017;12:e0171467.

11. New ROP risk model [Internet]. American Academy of Ophthalmology. 2016 [cited 2019 Sep 3]. Available from: https://www.aao.org/pediatric-center-detail/new-rop-risk-model-3

12. Gunn TR, Easdown J, Outerbridge EW, Aranda JV. Risk factors in retrolental fibroplasia. Pediatrics. 1980;65:1096-100.

13. Smith LE. Pathogenesis of retinopathy of prematurity. Growth Horm IGF Res. 2004;14 Suppl A:S140-4.

14. Hellström A, Ley D, Hansen-Pupp I, Hallberg B, Ramenghi LA, Löfqvist C, et al. IGF-I in the clinics: use in retinopathy of prematurity. Growth Horm IGF Res. 2016;30-31:7-80.

15. Chen J, Stahl A, Hellstrom A, Smith LE. Current update on retinopathy of prematurity: screening and treatment. Curr Opin Pediatr. 2011;23:173-8.

16. Gong Y, Fu Z, Liegl R, Chen J, Hellström A, Smith LE. $\omega-3$ and $\omega-6$ long-chain PUFAs and their enzymatic metabolites in neovascular eye diseases. Am J Clin Nutr. 2017;106:16-26.

17. Slidsborg C, Jensen A, Forman JL, Rasmussen S, Bangsgaard R, Fledelius HC, et al. Neonatal risk factors for treatment-demanding retinopathy of prematurity: a danish national study. Ophthalmology. 2016;123:796-803.

18. Azami M, Jaafari Z, Rahmati S, Farahani AD, Badfar G. Prevalence and risk factors of retinopathy of prematurity in Iran: a systematic review and meta-analysis. BMC Ophthalmol. 2018;18:83.

19. Cao JH, Wagner BD, McCourt EA, Cerda A, Sillau S, Palestine A, et al. The Colorado-retinopathy of prematurity model (CO-ROP): postnatal weight gain screening algorithm. J AAPOS. 2016;20:19-24.

20. SUPPORT Study Group of the Eunice Kennedy Shriver NICHD Neonatal Research Network; Carlo WA, Finer NN, Walsh MC, Rich W, Gantz MG, Laptook AR, et al. Target ranges of oxygen saturation in extremely preterm infants. N Engl J Med. 2010;362:1959-69. 
21. Schmidt B, Whyte RK, Asztalos EV, Moddemann D, Poets C, Rabi Y, et al; Canadian Oxygen Trial (COT) Group. Effects of targeting higher vs lower arterial oxygen saturations on death or disability in extremely preterm infants: a randomized clinical trial. JAMA. 2013;309:2111-20.

22. Good WV; Early Treatment for Retinopathy of Prematurity Cooperative Group. Final results of the Early Treatment for Retinopathy of Prematurity (ETROP) randomized trial. Trans Am Ophthalmol Soc. 2004;102:233-50.

23. Cryotherapy for Retinopathy of Prematurity Cooperative Group. Multicenter trial of cryotherapy for retinopathy of prematurity: ophthalmological outcomes at 10 years. Arch Ophthalmol. 2001;119:1110-8.

24. Nicolaides KH, Economides DL, Soothill PW. Blood gases, pH, and lactate in appropriate- and small-forgestational-age fetuses. Am J Obstet Gynecol. 1989;161:996-1001.

25. Giusti B, Vestrini A, Poggi C, Magi A, Pasquini E, Abbate R, et al. Genetic polymorphisms of antioxidant enzymes as risk factors for oxidative stress-associated complications in preterm infants. Free Radic Res. 2012;46:1130-9.

26. Buonocore G, Perrone S, Longini M, Vezzosi P, Marzocchi B, Paffetti P, et al. Oxidative stress in preterm neonates at birth and on the seventh day of life. Pediatr Res. 2002;52:46-9.

27. Skouroliakou M, Konstantinou D, Koutri K, Kakavelaki C, Stathopoulou M, Antoniadi M, et al. A doubleblind, randomized clinical trial of the effect of omega-3 fatty acids on the oxidative stress of preterm neonates fed through parenteral nutrition. Eur J Clin Nutr. 2010;64:940-7.

28. Stone J, Itin A, Alon T, Pe'er J, Gnessin H, Chan-Ling T, et al. Development of retinal vasculature is mediated by hypoxia-induced vascular endothelial growth factor (VEGF) expression by neuroglia. J Neurosci. 1995;15:4738-47.

29. Darwish D, Chee R-I, Patel SN, Jonas K, Ostmo S, Campbell JP, et al. Anti-vascular endothelial growth factor and the evolving management paradigm for retinopathy of prematurity. Asia Pac J Ophthalmol (Phila). 2018;7:136-44.

30. Kara C, Hekimoğlu E, Petriçli İS, Akıl H. Intravitreal bevacizumab as rescue therapy following treatment failure with laser photocoagulation in retinopathy of prematurity. J Curr Ophthalmol. 2017;30:80-4.

31. Yoon JM, Shin DH, Kim SJ, Ham DI, Kang SW, Chang YS, et al. Outcomes after laser versus combined laser and bevacizumab treatment for type 1 retinopathy of prematurity in zone I. Retina. 2017;37:88-96.

32. Alon T, Hemo I, Itin A, Pe'er J, Stone J, Keshet E. Vascular endothelial growth factor acts as a survival factor for newly formed retinal vessels and has implications for retinopathy of prematurity. Nat Med. 1995;1:1024-8.

33. Shweiki D, Itin A, Soffer D, Keshet E. Vascular endothelial growth factor induced by hypoxia may mediate hypoxia-initiated angiogenesis. Nature. 1992;359:843-5.

34. Aiello LP, Pierce EA, Foley ED, Takagi H, Chen H, Riddle L, et al. Suppression of retinal neovascularization in vivo by inhibition of vascular endothelial growth factor (VEGF) using soluble VEGF-receptor chimeric proteins. Proc Natl Acad Sci U S A. 1995;92:10457-61.

35. Mintz-Hittner HA, Kennedy KA, Chuang AZ; BEAT-ROP Cooperative Group. Efficacy of intravitreal bevacizumab for stage 3+ retinopathy of prematurity. N Engl J Med. 2011;364:603-15.

36. Mintz-Hittner HA, Kuffel RR Jr. Intravitreal injection of bevacizumab (avastin) for treatment of stage 3 retinopathy of prematurity in zone I or posterior zone II. Retina. 2008;28:831-8.

37. Chung EJ, Kim JH, Ahn HS, Koh HJ. Combination of laser photocoagulation and intravitreal bevacizumab (avastin) for aggressive zone I retinopathy of prematurity. Graefes Arch Clin Exp Ophthalmol. 2007;245:1727-30.

38. Raghuram K, Isaac M, Yang J, AlAli A, Mireskandari K, Ly LG, et al. Neurodevelopmental outcomes in infants treated with intravitreal bevacizumab versus laser. J Perinatol. 2019;39:1300-8.

39. Natarajan G, Shankaran S, Nolen TL, Sridhar A, Kennedy KA, Hintz SR, et al. Neurodevelopmental outcomes of preterm infants with retinopathy of prematurity by treatment. Pediatrics. 2019;144:e20183537. 
40. Chang YS, Chen YT, Lai TT, Chou HC, Chen CY, Hsieh WS, et al. Involution of retinopathy of prematurity and neurodevelopmental outcomes after intravitreal bevacizumab treatment. PloS One. 2019;14:e0223972.

41. Barry GP, Tauber KA, Fisher M, Greenberg S, Zobal-Ratner J, Binenbaum G. Short-term retinal detachment risk after treatment of type 1 retinopathy of prematurity with laser photocoagulation versus intravitreal bevacizumab. J AAPOS. 2019;23:260.

42. Roohipoor R, Karkhaneh R, Riazi-Esfahani M, Dastjani Farahani A, Khodabandeh A, Ebrahimi Adib N, et al. Comparison of intravitreal bevacizumab and laser photocoagulation in the treatment of retinopathy of prematurity. Ophthalmol Retina. 2018;2:942-8.

43. Mansukhani SA, Hutchinson AK, Neustein R, Schertzer J, Allen JC, Hubbard GB. Fluorescein angiography in retinopathy of prematurity: comparison of infants treated with bevacizumab to those with spontaneous regression. Ophthalmol Retina. 2019;3:436-43.

44. Fu S, Dong S, Zhu M, Le Y-Z. VEGF as a trophic factor for Müller glia in hypoxic retinal diseases. Adv Exp Med Biol. 2018;1074:473-8.

45. Foxton RH, Finkelstein A, Vijay S, Dahlmann-Noor A, Khaw PT, Morgan JE, et al. VEGF-A is necessary and sufficient for retinal neuroprotection in models of experimental glaucoma. Am J Pathol. 2013;182:1379-90.

46. Sato T, Wada K, Arahori H, Kuno N, Imoto K, Iwahashi-Shima C, et al. Serum concentrations of bevacizumab (avastin) and vascular endothelial growth factor in infants with retinopathy of prematurity. Am J Ophthalmol. 2012;153:327-33.

47. Wu WC, Shih CP, Lien R, Wang NK, Chen YP, Chao AN, et al. Serum vascular endothelial growth factor after bevacizumab or ranibizumab treatment for retinopathy of prematurity. Retina. 2017;37:694-701.

48. Hellgren G, Löfqvist C, Hård AL, Hansen-Pupp I, Gram M, Ley D, et al. Serum concentrations of vascular endothelial growth factor in relation to retinopathy of prematurity. Pediatr Res. 2016;79:70-5.

49. Wu WC, Lien R, Liao PJ, Wang NK, Chen YP, Chao AN, et al. Serum levels of vascular endothelial growth factor and related factors after intravitreous bevacizumab injection for retinopathy of prematurity. JAMA Ophthalmol. 2015;133:391-7.

50. VanderVeen DK, Melia M, Yang MB, Hutchinson AK, Wilson LB, Lambert SR. Anti-vascular endothelial growth factor therapy for primary treatment of type 1 retinopathy of prematurity: a report by the American Academy of Ophthalmology. Ophthalmology. 2017;124:619-33.

51. Stahl A, Krohne TU, Eter N, Oberacher-Velten I, Guthoff R, Meltendorf S, et al; Comparing Alternative Ranibizumab Dosages for Safety and Efficacy in Retinopathy of Prematurity (CARE-ROP) Study Group. Comparing alternative ranibizumab dosages for safety and efficacy in retinopathy of prematurity: a randomized clinical trial. JAMA Pediatr. 2018;172:278-86.

52. Axer-Siegel R, Snir M, Cotlear D, Maayan A, Frilling R, Rosenbaltt I, et al. Diode laser treatment of posterior retinopathy of prematurity. Br J Ophthalmol. 2000;84:1383-6.

53. O'Keefe M, O'Reilly J, Lanigan B. Longer-term visual outcome of eyes with retinopathy of prematurity treated with cryotherapy or diode laser. Br J Ophthalmol. 1998;82:1246-8.

54. Askie LM, Darlow BA, Davis PG, Finer N, Stenson B, Vento M, et al. Effects of targeting lower versus higher arterial oxygen saturations on death or disability in preterm infants. Cochrane Database Syst Rev. 2017;4:CD011190.

55. Darlow BA, Vento M, Beltempo M, Lehtonen L, Håkansson S, Reichman B, et al; on behalf of the International Network for Evaluating Outcomes (iNeo) of Neonates. Variations in oxygen saturation targeting, and retinopathy of prematurity screening and treatment criteria in neonatal intensive care units: an international survey. Neonatology. 2018;114:323-31.

56. BOOST II United Kingdom Collaborative Group; BOOST II Australia Collaborative Group; BOOST II New Zealand Collaborative Group; Stenson BJ, Tarnow-Mordi WO, Darlow BA, Simes J, Juszczak E, Askie L, et al. Oxygen saturation and outcomes in preterm infants. N Engl J Med. 2013;368:2094-104. 
57. Mouradian GC, Alvarez-Argote S, Gorzek R, Thuku G, Michkalkiewicz T, Wong-Riley MTT, et al. Acute and chronic changes in the control of breathing in a rat model of bronchopulmonary dysplasia. Am J Physiol Lung Cell Mol Physiol. 2019;316:L506-18.

58. Singh JK, Wymore EM, Wagner BD, Thevarajah TS, Jung JL, Kinsella JP, et al. Relationship between severe bronchopulmonary dysplasia and severe retinopathy of prematurity in premature newborns. J AAPOS. 2019;23:209.e1-4.

59. Jensen AK, Ying G-S, Huang J, Quinn GE, Binenbaum G. Longitudinal study of the association between thrombocytopenia and retinopathy of prematurity. J AAPOS. 2018;22:119-23.

60. Lundgren P, Hellgren G, Pivodic A, Sävman K, Smith LEH, Hellström A. Erythropoietin serum levels, versus anaemia as risk factors for severe retinopathy of prematurity. Pediatr Res. 2019;86:276-82.

61. Lust C, Vesoulis Z, Jackups R, Liao S, Rao R, Mathur AM. Early red cell transfusion is associated with development of severe retinopathy of prematurity. J Perinatol. 2019;39:393-400.

62. Ghirardello S, Dusi E, Cortinovis I, Villa S, Fumagalli M, Agosti M, et al. Effects of red blood cell transfusions on the risk of developing complications or death: an observational study of a cohort of very low birth weight infants. Am J Perinatol. 2017;34:88-95.

63. Smith LEH. IGF-1 and retinopathy of prematurity in the preterm infant. Biol Neonate. 2005;88:237-44.

64. Jensen AK, Ying GS, Huang J, Quinn GE, Binenbaum G. Postnatal serum insulin-like growth factor I and retinopathy of prematurity. Retina. 2017;37:867-72.

65. Hellström A, Engström E, Hård AL, Albertsson-Wikland K, Carlsson B, Niklasson A, et al. Postnatal serum insulin-like growth factor I deficiency is associated with retinopathy of prematurity and other complications of premature birth. Pediatrics. 2003;112:1016-20.

66. Coşkun Y, Dalkan C, Yabaş Ö, Demirel ÖÜ, Bayar ES, Sakarya S, et al. A predictive score for retinopathy of prematurity by using clinical risk factors and serum insulin-like growth factor-1 levels. Int J Ophthalmol. 2017;10:1722-7.

67. Pérez-Muñuzuri A, Couce-Pico ML, Baña-Souto A, López-Suárez O, Iglesias-Deus A, Blanco-Teijeiro J, et al. Preclinical screening for retinopathy of prematurity risk using IGF1 levels at 3 weeks post-partum. PLoS One. 2014;9:e88781.

68. Hellstrom A, Perruzzi C, Ju M, Engstrom E, Hard AL, Liu JL et al. Low IGF-I suppresses VEGF-survival signaling in retinal endothelial cells: direct correlation with clinical retinopathy of prematurity. Proc Natl Acad Sci U S A. 2001;98:5804-8.

69. Smith LE, Shen W, Perruzzi C, Soker S, Kinose F, Xu X, et al. Regulation of vascular endothelial growth factordependent retinal neovascularization by insulin-like growth factor-1 receptor. Nat Med. 1999;5:1390-5.

70. Lofqvist C, Chen J, Connor KM, Smith AC, Aderman CM, Liu N, et al. IGFBP3 suppresses retinopathy through suppression of oxygen-induced vessel loss and promotion of vascular regrowth. Proc Natl Acad Sci U S A. 2007;104:10589-94.

71. IGF-1/IGFBP3 Prevention of Retinopathy of Prematurity [Internet]. ClinicalTrials.gov. 2017 [cited 2019 Oct 18]. Available from: https://clinicaltrials.gov/ct2/show/NCT01096784

72. Ley D, Hansen-Pupp I, Niklasson A, Domellöf M, Friberg LE, Borg J, et al. Longitudinal infusion of a complex of insulin-like growth factor-I and IGF-binding protein-3 in five preterm infants: pharmacokinetics and short-term safety. Pediatr Res. 2013;73:68-74.

73. Ley D, Hallberg B, Hansen-Pupp I, Dani C, Ramenghi LA, Marlow N, et al; study team. rhIGF-1/rhIGFBP-3 in preterm infants: a phase 2 randomized controlled trial. J Pediatr. 2019;206:56-65.

74. Bianchi VE, Locatelli V, Rizzi L. Neurotrophic and neuroregenerative effects of GH/IGF1. Int J Mol Sci. 2017;18:E2441.

75. Stroka DM, Burkhardt T, Desbaillets I, Wenger RH, Neil DA, Bauer C, et al. HIF-1 is expressed in normoxic tissue and displays an organ-specific regulation under systemic hypoxia. FASEB J. 2001;15:2445-53. 
76. Vadlapatla RK, Vadlapudi AD, Mitra AK. Hypoxia-inducible factor-1 (HIF-1): a potential target for intervention in ocular neovascular diseases. Curr Drug Targets. 2013;14:919-35.

77. Sears JE, Hoppe G, Ebrahem Q Anand-Apte B. Prolyl hydroxylase inhibition during hyperoxia prevents oxygen-induced retinopathy. Proc Natl Acad Sci U S A. 2008;105:19898-903.

78. Trichonas G, Lee TJ, Hoppe G, Au J, Sears JE. Prolyl hydroxylase inhibition during hyperoxia prevents oxygen-induced retinopathy in the rat 50/10 model. Invest Ophthalmol Vis Sci. 2013;54:4919-26.

79. Hoppe G, Yoon S, Gopalan B, Savage AR, Brown R, Case K, et al. Comparative systems pharmacology of HIF stabilization in the prevention of retinopathy of prematurity. Proc Natl Acad Sci U S A. 2016;113:E2516-25.

80. Singh C, Sharma A, Hoppe G, Song W, Bolok Y, Sears JE. 3-Hydroxypyruvate destabilizes hypoxia inducible factor and induces angiostasis. Invest Ophthalmol Vis Sci. 2018;59:3440-8.

81. Miwa Y, Hoshino Y, Shoda C, Jiang X, Tsubota K, Kurihara T. Pharmacological HIF inhibition prevents retinal neovascularization with improved visual function in a murine oxygen-induced retinopathy model. Neurochem Int. 2019;128:21-31.

82. Kim JH, Kim JH, Yu YS, Shin JY, Lee HY, Kim KW. Deguelin inhibits retinal neovascularization by downregulation of HIF-1alpha in oxygen-induced retinopathy. J Cell Mol Med. 2008;12:2407-15.

83. Schmidt B, Roberts RS, Davis P, Doyle LW, Barrington KJ, Ohlsson A, et al; Caffeine for Apnea of Prematurity Trial Group. Long-term effects of caffeine therapy for apnea of prematurity. N Engl J Med. 2007;357:1893-902.

84. Park SH, Yum HR, Kim S, Lee YC. Retinopathy of prematurity in Korean infants with birthweight greater than 1500 g. Br J Ophthalmol. 2016;100:834-8.

85. Kua KP, Lee SW. Systematic review and meta-analysis of clinical outcomes of early caffeine therapy in preterm neonates. Br J Clin Pharmacol. 2017;83:180-91.

86. Zhang S, Zhou R, Li B, Li H, Wang Y, Gu X, et al. Caffeine preferentially protects against oxygen-induced retinopathy. FASEB J. 2017;31:3334-48.

87. Aranda JV, Cai CL, Ahmad T, Bronshtein V, Sadeh J, Valencia GB, et al. Pharmacologic synergism of ocular ketorolac and systemic caffeine citrate in rat oxygen-induced retinopathy. Pediatr Res. 2016;80:554-65.

88. Giannantonio C, Papacci P, Purcaro V, Cota F, Tesfagabir MG, Molle F, et al. Effectiveness of ketorolac tromethamine in prevention of severe retinopathy of prematurity. J Pediatr Ophthalmol Strabismus. 2011;48:247-51.

89. Hwang JH, Koh EJ, Lee YJ, Chio J, Song JH, Seo YJ, et al. Anti-inflammatory effect of caffeine by regulating NF- $\kappa B$ activation in murine macrophage. FASEB J. 2016;30:lb256.

90. Lodha A, Entz R, Synnes A, Creighton D, Yusuf K, Lapointe A, et al; investigators of the Canadian Neonatal Network (CNN) and the Canadian Neonatal Follow-up Network (CNFUN). Early caffeine administration and neurodevelopmental outcomes in preterm infants. Pediatrics. 2019;143:e20181348.

91. Léauté-Labrèze C, Hoeger P, Mazereeuw-Hautier J, Guibaud L, Baselga E, Posiunas G, et al. A randomized, controlled trial of oral propranolol in infantile hemangioma. N Engl J Med. 2015;372:735-46.

92. Wei L, Li L, Zhang B, Ma L. Propranolol suppresses cobalt chloride-induced hypoxic proliferation in human umbilical vein endothelial cells in vitro. Pharmacology. 2019;103:61-7.

93. Zhang L, Mai HM, Zheng J, Zheng JW, Wang YA, Qin ZP, et al. Propranolol inhibits angiogenesis via downregulating the expression of vascular endothelial growth factor in hemangioma derived stem cell. Int J Clin Exp Pathol. 2013;7:48-55.

94. Zhao F, Yang X, Xu G, Bi J, Lv R, Huo R. Propranolol suppresses HUVEC viability, migration, VEGF expression, and promotes apoptosis by downregulation of miR-4295. J Cell Biochem. 2019;120:6614-23.

95. Ristori C, Filippi L, Dal Monte M, Martini D, Cammalleri M, Fortunato P, et al. Role of the adrenergic system in a mouse model of oxygen-induced retinopathy: antiangiogenic effects of beta-adrenoreceptor blockade. Invest Ophthalmol Vis Sci. 2011;52:155-70. 
96. Dal Monte M, Martini D, Latina V, Pavan B, Filippi L, Bagnoli P. Beta-adrenoreceptor agonism influences retinal responses to hypoxia in a model of retinopathy of prematurity. Invest Ophthalmol Vis Sci. 2012;53:2181-92.

97. Chen J, Joyal JS, Hatton CJ, Juan AM, Pei DT, Hurst CG, et al. Propranolol inhibition of $\beta$-adrenergic receptor does not suppress pathologic neovascularization in oxygen-induced retinopathy. Invest Ophthalmol Vis Sci. 2012;53:2968-77.

98. Dal Monte M, Casini G, la Marca G, Isacchi B, Filippi L, Bagnoli P. Eye drop propranolol administration promotes the recovery of oxygen-induced retinopathy in mice. Exp Eye Res. 2013;111:27-35.

99. Yun JH, Koh YJ, Jeong HS, Lee DH, Lee EH, Cho CH. Propranolol increases vascular permeability through pericyte apoptosis and exacerbates oxygen-induced retinopathy. Biochem Biophys Res Commun. 2018;503:2792-9.

100. Makhoul IR, Peleg O, Miller B, Bar-Oz B, Kochavi O, Mechoulam H, et al. Oral propranolol versus placebo for retinopathy of prematurity: a pilot, randomised, double-blind prospective study. Arch Dis Child. 2013;98:565-7.

101. Filippi L, Cavallaro G, Berti E, Padrini L, Araimo G, Regiroli G, et al. Propranolol 0.2\% eye micro-drops for retinopathy of prematurity: a prospective phase IIB study. Front Pediatr. 2019;7:180.

102. Korkmaz L, Karaca C, Akin MA, Bastug O, Sahiner M, Ozdemir A, et al. Short-term refractive effects of propranolol hydrochloride prophylaxis on retinopathy of prematurity in very preterm newborns. Curr Eye Res. 2018;43:213-7.

103. Sanghvi KP, Kabra NS, Padhi P, Singh U, Dash SK, Avasthi BS. Prophylactic propranolol for prevention of ROP and visual outcome at 1 year (PreROP trial). Arch Dis Child Fetal Neonatal Ed. 2017;102:F389-94.

104. Stritzke A, Kabra N, Kaur S, Robertson HL, Lodha A. Oral propranolol in prevention of severe retinopathy of prematurity: a systematic review and meta-analysis. J Perinatol. 2019;39:1695.

105. Chen ML, Allred EN, Hecht JL, Onderdonk A, VanderVeen D, Wallace DK, et al; ELGAN Study. Placenta microbiology and histology and the risk for severe retinopathy of prematurity. Invest Ophthalmol Vis Sci. 2011;52:7052-8.

106. Sood BG, Madan A, Saha S, Schendel D, Thorsen P, Skogstrand K et al. Perinatal systemic inflammatory response syndrome and retinopathy of prematurity. Pediatr Res. 2010;67:394-400.

107. Park YJ, Woo SJ, Kim YM, Hong S, Lee YE, Park KH. Immune and inflammatory proteins in cord blood as predictive biomarkers of retinopathy of prematurity in preterm infants. Invest Ophthalmol Vis Sci. 2019;60:3813-20.

108. Thakkar SK, De Castro CA, Beauport L, Tolsa JF, Fischer Fumeaux CJ, Affolter M, et al. Temporal progression of fatty acids in preterm and term human milk of mothers from Switzerland. Nutrients. 2019;11:E112.

109. Makrides M, Best K, Yelland L, McPhee A, Zhou S, Quinlivan J, et al. A randomized trial of prenatal n-3 fatty acid supplementation and preterm delivery. N Engl J Med. 2019 12;381:1035-45.

110. Malikiwi AI, Lee YM, Davies-Tuck M, Wong FY. Postnatal nutritional deficit is an independent predictor of bronchopulmonary dysplasia among extremely premature infants born at or less than 28 weeks gestation. Early Hum Dev. 2019;131:29-35.

111. Klevebro S, Lundgren P, Hammar U, Smith LE, Bottai M, Domellöf M, et al. Cohort study of growth patterns by gestational age in preterm infants developing morbidity. BMJ Open. 2016 17;6:e012872.

112. Wu C, Löfqvist C, Smith LE, VanderVeen DK, Hellström A; WINROP Consortium. Importance of early postnatal weight gain for normal retinal angiogenesis in very preterm infants: a multicenter study analyzing weight velocity deviations for the prediction of retinopathy of prematurity. Arch Ophthalmol. 2012;130:992-9.

113. Binenbaum G, Ying GS, Quinn GE, Huang J, Dreiseitl S, Antigua J, etal. The CHOP postnatal weight gain, birth weight, and gestational age retinopathy of prematurity risk model. Arch Ophthalmol. 2012;130:1560-5. 
114. Binenbaum G, Ying GS, Tomlinson LA; Postnatal Growth and Retinopathy of Prematurity (G-ROP) Study Group. Validation of the Children's Hospital of Philadelphia Retinopathy of Prematurity (CHOP ROP) model. JAMA Ophthalmol. 2017;135:871-7.

115. Manzoni P, Stolfi I, Pedicino R, Vagnarelli F, Mosca F, Pugni L, et al; Italian Task Force for the Study and Prevention of Neonatal Fungal Infections; Italian Society of Neonatology. Human milk feeding prevents retinopathy of prematurity (ROP) in preterm VLBW neonates. Early Hum Dev. 2013;89 Suppl 1:S64-8.

116. Miller J, Tonkin E, Damarell RA, McPhee AJ, Suganuma M, Suganuma H, et al. A systematic review and meta-analysis of human milk feeding and morbidity in very low birth weight infants. Nutrients. 2018;10:E707.

117. Bharwani SK, Green BF, Pezzullo JC, Bharwani SS, Bharwani SS, Dhanireddy R. Systematic review and meta-analysis of human milk intake and retinopathy of prematurity: a significant update. J Perinatol. 2016;36:913-20.

118. Ginovart G, Gich I, Verd S. Human milk feeding protects very low-birth-weight infants from retinopathy of prematurity: a pre-post cohort analysis. J Matern-Fetal Neonatal Med. 2016;29:3790-5.

119. Sbrizzi S, Quitadamo PA, Ravidà D, Palumbo G, Cristalli PP, Pettoello-Mantovani M. Analytical study of donor's milk bank macronutrients by infrared spectroscopy. Correlations with clinic-metabolic profile of 100 donors. Front Public Health. 2019;7:234.

120. Wesolowska A, Sinkiewicz-Darol E, Barbarska O, Bernatowicz-Lojko U, Borszewska-Kornacka MK, van Goudoever JB. Innovative techniques of processing human milk to preserve key components. Nutrients. 2019;11:E1169.

121. Owens WC, Owens EU. Retrolental fibroplasia in premature infants; studies on the prophylaxis of the disease; the use of alpha tocopheryl acetate. Am J Ophthalmol. 1949;32:1631-7.

122. Effect of vitamin $\mathrm{E}$ for prevention of retinopathy of prematurity: a randomized clinical trial. ClinicalTrials. gov. [Internet]. [cited 2019 Oct 18]. Available from: https://clinicaltrials.gov/ct2/show/NCT03274596

123. Friedman CA, McVey J, Borne MJ, James M, May WL, Temple DM, et al. Relationship between serum inositol concentration and development of retinopathy of prematurity: a prospective study. J Pediatr Ophthalmol Strabismus. 2000;37:79-86.

124. Hallman M, Bry K, Hoppu K, Lappi M, Pohjavuori M. Inositol supplementation in premature infants with respiratory distress syndrome. N Engl J Med. 1992;326:1233-9.

125. Phelps DL, Watterberg KL, Nolen TL, Cole CA, Cotten CM, Oh W, et al; Eunice Kennedy Shriver National Institute of Child Health and Human Development Neonatal Research Network. Effects of myo-inositol on type 1 retinopathy of prematurity among preterm infants $<28$ weeks' gestational age: a randomized clinical trial. JAMA. 2018;320:1649-58.

126. Du Y, He Y, Wang YL, Zhou JG, Chen C. The efficacy and safety of inositol supplementation in preterm infants to prevent retinopathy of prematurity: a systematic review and meta-analysis. BMC Ophthalmol. 2019;19:135.

127. Howlett A, Ohlsson A, Plakkal N. Inositol in preterm infants at risk for or having respiratory distress syndrome. Cochrane Database Syst Rev. 2019;7:CD000366.

128. Chen HJ, Hsu CH, Chiang BL. Serum retinol levels and neonatal outcomes in preterm infants. J Formos Med Assoc. 2017;116:626-33.

129. Garofoli F, Mazzucchelli I, Decembrino L, Bartoli A, Angelini M, Broglia M, et al. Levels and effectiveness of oral retinol supplementation in VLBW preterm infants. Int J Immunopathol Pharmacol. 2018;32:2058738418820484.

130. Fang JL, Sorita A, Carey WA, Colby CE, Murad MH, Alahdab F. Interventions to prevent retinopathy of prematurity: a meta-analysis. Pediatrics. 2016;137:e20153387.

131. Mactier H, McCulloch DL, Hamilton R, Galloway P, Bradnam MS, Young D, et al. Vitamin A supplementation improves retinal function in infants at risk of retinopathy of prematurity. J Pediatr. 2012;160:954-9. 
132. Sun H, Cheng R, Wang Z. Early vitamin A supplementation improves the outcome of retinopathy of prematurity in extremely preterm infants. Retina. 2019; [Epub ahead of print].

133. Hortensius LM, van Elburg RM, Nijboer CH, Benders MJNL, de Theije CGM. Postnatal nutrition to improve brain development in the preterm infant: a systematic review from bench to bedside. Front Physiol. 2019;10:961.

134. Abribat T, Nedelec B, Jobin N, Garrel DR. Decreased serum insulin-like growth factor-I in burn patients: relationship with serum insulin-like growth factor binding protein-3 proteolysis and the influence of lipid composition in nutritional support. Crit Care Med. 2000;28:2366-72.

135. Calviello G, Di Nicuolo F, Gragnoli S, Piccioni E, Serini S, Maggiano N, et al. n-3 PUFAs reduce VEGF expression in human colon cancer cells modulating the COX-2/PGE2 induced ERK-1 and -2 and HIF1alpha induction pathway. Carcinogenesis. 2004;25:2303-10.

136. Szymczak M, Murray M, Petrovic N. Modulation of angiogenesis by omega-3 polyunsaturated fatty acids is mediated by cyclooxygenases. Blood. 2008;111:3514-21.

137. Connor KM, SanGiovanni JP, Lofqvist C, Aderman CM, Chen J, Higuchi A, et al. Increased dietary intake of omega-3-polyunsaturated fatty acids reduces pathological retinal angiogenesis. Nat Med. 2007;13:868-73.

138. Stahl A, Sapieha P, Connor KM, Sangiovanni JP, Chen J, Aderman CM, et al. Short communication: PPAR gamma mediates a direct antiangiogenic effect of omega 3-PUFAs in proliferative retinopathy. Circ Res. 2010;107:495-500.

139. Beharry KD, Cai CL, Siddiqui F, Chowdhury S, D'Agrosa C, Valencia GB, et al. Comparative effects of coenzyme Q10 or n-3 polyunsaturated fatty acid supplementation on retinal angiogenesis in a rat model of oxygen-induced retinopathy. Antioxidants (Basel). 2018;7:E160.

140. Gajos G, Zalewski J, Rostoff P, Nessler J, Piwowarska W, Undas A. Reduced thrombin formation and altered fibrin clot properties induced by polyunsaturated omega-3 fatty acids on top of dual antiplatelet therapy in patients undergoing percutaneous coronary intervention (OMEGA-PCI clot). Arterioscler Thromb Vasc Biol. 2011;31:1696-702.

141. Beken S, Dilli D, Fettah ND, Kabataş EU, Zenciroğlu A, Okumuş N. The influence of fish-oil lipid emulsions on retinopathy of prematurity in very low birth weight infants: a randomized controlled trial. Early Hum Dev. 2014;90:27-31.

142. Najm S, Löfqvist C, Hellgren G, Engström E, Lundgren P, Hård AL, et al. Effects of a lipid emulsion containing fish oil on polyunsaturated fatty acid profiles, growth and morbidities in extremely premature infants: a randomized controlled trial. Clin Nutr ESPEN. 2017;20:17-23.

143. Pawlik D, Lauterbach R, Turyk E. Fish-oil fat emulsion supplementation may reduce the risk of severe retinopathy in VLBW infants. Pediatrics. 2011;127:223-8.

144. Pawlik D, Lauterbach R, Walczak M, Hurkała J, Sherman MP. Fish-oil fat emulsion supplementation reduces the risk of retinopathy in very low birth weight infants: a prospective, randomized study. JPEN J Parenter Enteral Nutr. 2014;38:711-6.

145. Vayalthrikkovil S, Bashir RA, Rabi Y, Amin H, Spence JM, Robertson HL, et al. Parenteral fish-oil lipid emulsions in the prevention of severe retinopathy of prematurity: a systematic review and metaanalysis. Am J Perinatol. 2017;34:705-15.

146. Repa A, Binder C, Thanhaeuser M, Kreissl A, Pablik E, Huber-Dangl M, et al. A mixed lipid emulsion for prevention of parenteral nutrition associated cholestasis in extremely low birth weight infants: a randomized clinical trial. J Pediatr. 2018;194:87-93.

147. Bernabe-García M, Villegas-Silva R, Villavicencio-Torres A, Calder PC, Rodríguez-Cruz M, MaldonadoHernández J, et al. Enteral docosahexaenoic acid and retinopathy of prematurity: a randomized clinical trial. JPEN J Parenter Enteral Nutr. 2019;43:874-82.

148. Collins CT, Makrides M, McPhee AJ, Sullivan TR, Davis PG, Thio M, et al. Docosahexaenoic acid and bronchopulmonary dysplasia in preterm infants. N Engl J Med. 2017;376:1245-55. 
149. Pallot C, Mazzocco J, Meillon C, Semama DS, Chantegret C, Ternoy N, et al. Alteration of erythrocyte membrane polyunsaturated fatty acids in preterm newborns with retinopathy of prematurity. Sci Rep. 2019;9:7930.

150. Swan R, Kim SJ, Campbell JP, Paul Chan RV, Sonmez K, Taylor KD, et al. The genetics of retinopathy of prematurity: a model for neovascular retinal disease. Ophthalmol Retina. 2018;2:949-62.

151. Ortega-Molina JM, Anaya-Alaminos R, Uberos-Fernández J, Solans-Pérez de Larraya A, Chaves-Samaniego MJ, Salgado-Miranda A, et al. Genetic and environmental influences on retinopathy of prematurity. Mediat Inflamm. 2015;2015:e764159.

152. Bizzarro MJ, Hussain N, Jonsson B, Feng R, Ment LR, Gruen JR, et al. Genetic susceptibility to retinopathy of prematurity. Pediatrics. 2006;118:1858-63.

153. Roescher AM, Timmer A, Erwich JJ, Bos AF. Placental pathology, perinatal death, neonatal outcome, and neurological development: a systematic review. PLoS One. 2014;9:e89419.

154. Barker DJ, Osmond C, Law CM. The intrauterine and early postnatal origins of cardiovascular disease and chronic bronchitis. J Epidemiol Community Health. 1989;43:237-40.

155. Drillien CM. A longitudinal study of the growth and development of prematurely and maturely born children. Arch Dis Child. 1959;34:37-45.

156. Khan N, Couper JJ. Low-birth-weight infants show earlier onset of IDDM. Diabetes Care. 1994;17:653-6.

157. Brett KE, Ferraro ZM, Yockell-Lelievre J, Gruslin A, Adamo KB. Maternal-fetal nutrient transport in pregnancy pathologies: the role of the placenta. Int J Mol Sci. 2014;15:16153-85.

158. Çakir U, Yildiz D, Kahvecioğlu D, Okulu E, Alan S, Erdeve Ö, et al. Placenta, secret witness of infant morbidities: the relationship between placental histology and outcome of the premature infant. Turk Patoloji Derg. 2019;35:28-35.

159. Mehta R, Nanjundaswamy S, Shen-Schwarz S, Petrova A. Neonatal morbidity and placental pathology. Indian J Pediatr. 2006;73:25-8.

160. Mestan KK, Check J, Minturn L, Yallapragada S, Farrow KN, Liu X, et al. Placental pathologic changes of maternal vascular underperfusion in bronchopulmonary dysplasia and pulmonary hypertension. Placenta. 2014;35:570-4.

161. Redline RW. Severe fetal placental vascular lesions in term infants with neurologic impairment. Am J Obstet Gynecol. 2005;192:452-7.

162. Nosarti C, Reichenberg A, Murray RM, Cnattingius S, Lambe MP, Yin L, et al. Preterm birth and psychiatric disorders in young adult life. Arch Gen Psychiatry. 2012;69:E1-8.

163. Tomlinson MS, Santos HP, Stewart JR, Joseph R, Leviton A, Onderdonk AB, et al; ELGAN Study Investigators. Neurocognitive and social-communicative function of children born very preterm at 10 years of age: associations with microorganisms recovered from the placenta parenchyma. J Perinatol. 2019; [Epub ahead of print].

164. Kuban KCK, Jara H, O'Shea TM, Heeren T, Joseph RM, Fichorova RN, et al; ELGAN Study Investigators. Association of circulating proinflammatory and anti-inflammatory protein biomarkers in extremely preterm born children with subsequent brain magnetic resonance imaging volumes and cognitive function at age 10 years. J Pediatr. 2019;210:81-90.

165. Holm M, Morken TS, Fichorova RN, VanderVeen DK, Allred EN, Dammann O, et al; ELGAN Study Neonatology and Ophthalmology Committees. Systemic inflammation-associated proteins and retinopathy of prematurity in infants born before the 28th week of gestation. Invest Ophthalmol Vis Sci. 2017;58:6419-28.

166. Dammann O, Phillips TM, Allred EN, O'Shea TM, Paneth N, Van Marter LJ, et al; ELGAN STUDY INVESTIGATORS. Mediators of fetal inflammation in extremely low gestational age newborns. Cytokine. 2001;13:234-9. 
167. Bulka CM, Dammann O, Santos HP Jr, VanderVeen DK, Smeester L, Fichorova R, et al. Placental CpG methylation of inflammation, angiogenic, and neurotrophic genes and retinopathy of prematurity. Invest Ophthalmol Vis Sci. 2019;60:2888-94.

168. Leviton A, Allred EN, Fichorova RN, VanderVeen DK, O’Shea TM, Kuban K, et al; ELGAN Study Investigators. Early postnatal IGF-1 and IGFBP-1 blood levels in extremely preterm infants: relationships with indicators of placental insufficiency and with systemic inflammation. Am J Perinatol. 2019;36:1442-52.

169. Sato M, Nishimaki S, Yokota S, Seki K, Horiguchi H, An H, et al. Severity of chorioamnionitis and neonatal outcome. J Obstet Gynaecol Res. 2011;37:1313-9.

170. Ogunyemi D, Murillo M, Jackson U, Hunter N, Alperson B. The relationship between placental histopathology findings and perinatal outcome in preterm infants. J Matern Fetal Neonatal Med. 2003;13:102-9.

171. Moscuzza F, Belcari F, Nardini V, Bartoli A, Domenici C, Cuttano A, et al. Correlation between placental histopathology and fetal/neonatal outcome: chorioamnionitis and funisitis are associated to intraventricular haemorrage and retinopathy of prematurity in preterm newborns. Gynecol Endocrinol. 2011;27:319-23.

172. Yu XD, Branch DW, Karumanchi SA, Zhang J. Preeclampsia and retinopathy of prematurity in preterm births. Pediatrics. 2012;130:e101-7.

173. Fortes Filho JB, Costa MC, Eckert GU, Santos PG, Silveira RC, Procianoy RS. Maternal preeclampsia protects preterm infants against severe retinopathy of prematurity. J Pediatr. 2011;158:372-6.

174. Marins LR, Anizelli LB, Romanowski MD, Sarquis AL. How does preeclampsia affect neonates? Highlights in the disease's immunity. J Matern Fetal Neonatal Med. 2019;32:1205-12.

175. Razak A, Florendo-Chin A, Banfield L, Abdul Wahab MG, McDonald S, Shah PS, et al. Pregnancy-induced hypertension and neonatal outcomes: a systematic review and meta-analysis. J Perinatol. 2018;38:46-53.

176. Shulman JP, Weng C, Wilkes J, Greene T, Hartnett ME. Association of maternal preeclampsia with infant risk of premature birth and retinopathy of prematurity. JAMA Ophthalmol. 2017;135:947-53.

177. Yau GS, Lee JW, Tam VT, Liu CC, Yip S, Cheng E, et al. Incidence and risk factors of retinopathy of prematurity from 2 neonatal intensive care units in a Hong Kong Chinese population. Asia Pac J Ophthalmol (Phila). 2016;5:185-91.

178. Morsing E, Maršál K, Ley D. Reduced prevalence of severe intraventricular hemorrhage in very preterm infants delivered after maternal preeclampsia. Neonatology. 2018;114:205-11.

179. Yau GS, Lee JW, Tam VT, Liu CC, Chu BC, Yuen CY. Incidence and risk factors for retinopathy of prematurity in extreme low birth weight Chinese infants. Int Ophthalmol. 2015;35:365-73.

180. Huang HC, Yang HI, Chou HC, Chen CY, Hsieh WS, Tsou KI, et al; Taiwan Premature Infant Developmental Collaborative Study Group. Preeclampsia and retinopathy of prematurity in very-low-birth-weight infants: a population-based study. PLoS One. 2015;10:e0143248.

181. Ozkan H, Cetinkaya M, Koksal N, Ozmen A, Ylldı M. Maternal preeclampsia is associated with an increased risk of retinopathy of prematurity. J Perinat Med. 2011;39:523-7.

182. Yang CY, Lien R, Yang PH, Chu SM, Hsu JF, Fu RH, et al. Analysis of incidence and risk factors of retinopathy of prematurity among very-low-birth-weight infants in North Taiwan. Pediatr Neonatol. 2011;52:321-6.

183. Chan PY, Tang SM, Au SC, Rong SS, Lau HH, Ko ST, et al. Association of gestational hypertensive disorders with retinopathy of prematurity: a systematic review and meta-analysis. Sci Rep. 2016;6:1-9.

184. Hirabayashi H, Honda S, Morioka I, Yokoyama N, Sugiyama D, Nishimura K, et al. Inhibitory effects of maternal smoking on the development of severe retinopathy of prematurity. Eye (Lond). 2010;24:1024-7.

185. Becker S, Wang H, Yu B, Brown R, Han X, Lane RH, et al. Protective effect of maternal uteroplacental insufficiency on oxygen-induced retinopathy in offspring: removing bias of premature birth. Sci Rep. 2017;7:42301. 
186. Than NG, Romero R, Tarca AL, Kekesi KA, Xu Y, Xu Z, et al. Integrated systems biology approach identifies novel maternal and placental pathways of preeclampsia. Front Immunol. 2018;9:1661.

187. Powers RW, Jeyabalan A, Clifton RG, Van Dorsten P, Hauth JC, Klebanoff MA, et al; Eunice Kennedy Shriver National Institute of Child Health Human Development Maternal-Fetal Medicine Units Network. Soluble fms-Like tyrosine kinase 1 (sFlt1), endoglin and placental growth factor (PIGF) in preeclampsia among high risk pregnancies. PLoS One. 2010;5:e13263.

188. Teoh SS, Zhao M, Wang Y, Chen Q Nie G. Serum HtrA1 is differentially regulated between early-onset and late-onset preeclampsia. Placenta. 2015;36:990-5.

189. Hentges C, Silveira R, Procianoy R. Angiogenic and antiangiogenic factors in preterm neonates born to mothers with and without preeclampsia. Am J Perinatol. 2015;32:1185-90.

190. Carruthers N, Booy A, Ballard J, Siroen DM, Han VK, Lajoie GA. Early onset preeclampsia is characterized by altered placental lipid metabolism and a premature increase in circulating FABP4. Nature Precedings. 2010;4885:1.

191. Löfqvist CA, Najm S, Hellgren G, Engström E, Sävman K, Nilsson AK, et al. Association of retinopathy of prematurity with low levels of arachidonic acid. JAMA Ophthalmol. 2018;136:271-7.

192. Fung CM, White JR, Brown AS, Gong H, Weitkamp JH, Frey MR, et al. Intrauterine growth restriction alters mouse intestinal architecture during development. PLoS One. 2016;11:e0146542.

193. Fung C, Brown A, Cox J, Callaway C, McKnight R, Lane R. Novel thromboxane A2 analog-induced IUGR mouse model. J Dev Orig Health Dis. 2011;2:291-301.

194. Fung CM, Yang Y, Fu Q Brown AS, Yu B, Callaway CW, et al. IUGR prevents IGF-1 upregulation in juvenile male mice by perturbing postnatal IGF-1 chromatin remodeling. Pediatr Res. 2015;78:14-23. 